\title{
Article
}

\section{Driving and sustaining culture change in Olympic sport performance teams: A first exploration and grounded theory}

Cruickshank, A., Collins, D., and Minten, S.

Available at http://clok.uclan.ac.uk/12258/

Cruickshank, A. ORCID: 0000-0002-8893-2341, Collins, D., ORCID: 0000-00027601-0454 and Minten, S. (2014) Driving and sustaining culture change in Olympic sport performance teams: A first exploration and grounded theory. Journal of Sport and Exercise Psychology, 36 (1). pp. 107-120. ISSN 0895-2779

It is advisable to refer to the publisher's version if you intend to cite from the work. http://dx.doi.org/10.1123/sep.2013-0133

For more information about UCLan's research in this area go to http://www.uclan.ac.uk/researchgroups/ and search for <name of research Group>.

For information about Research generally at UCLan please go to http://www.uclan.ac.uk/research/

All outputs in CLoK are protected by Intellectual Property Rights law, including Copyright law. Copyright, IPR and Moral Rights for the works on this site are retained by the individual authors and/or other copyright owners. Terms and conditions for use of this material are defined in the policies page.

\section{CLoK}

Central Lancashire online Knowledge www.clok.uclan.ac.uk

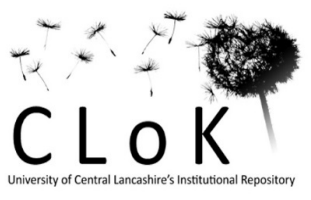


This is an Author Accepted Manuscript, as accepted for publication, of an article published by Human Kinetics in Journal of Sport and Exercise Psychology in February 2014, available online: http://journals.humankinetics.com/jsep-back-issues/jsep-volume-36-issue-1february/driving-and-sustaining-culture-change-in-olympic-sport-performance-teams-a-firstexploration-and-grounded-theory

PLEASE REFER TO THE PUBLISHED VERSION FOR CITING PURPOSES

Driving and Sustaining Culture Change in Olympic Sport Performance Teams: A First Exploration and Grounded Theory

Andrew Cruickshank ${ }^{1}$, Dave Collins ${ }^{1} \&$ Sue Minten ${ }^{2}$

${ }^{1}$ Institute of Coaching and Performance, University of Central Lancashire

${ }^{2}$ School of Sport, Tourism and The Outdoors, University of Central Lancashire 


\begin{abstract}
Stimulated by growing interest in the organizational and performance leadership components of Olympic success, sport psychology researchers have identified Performance Director-led culture change as a process of particular theoretical and applied significance. To build on initial work in this area, and develop practically meaningful understanding, a pragmatic research philosophy and grounded theory methodology were engaged to uncover culture change best practice from the perspective of newly appointed Performance Directors. Delivered in complex and contested settings, results revealed that the optimal change process consisted of an initial evaluation, planning, and impact phase adjoined to the immediate and enduring management of a multi-directional, perception- and power-based social system. As the first inquiry of its kind, these findings provide a foundation for the continued theoretical development of culture change in Olympic sport performance teams and a first model on which applied practice can be based.
\end{abstract}

Keywords: change management, elite sport, management, success cultures, succession 


\section{Driving and Sustaining Culture Change in Olympic Sport Performance Teams: A First Exploration and Grounded Theory}

As one of the most significant global sporting events, preparation for and performance at the Olympic Games has long been an area of intrigue for sport psychologists. Reflecting this interest, scholars and consultants are continually seeking new ways in which success can be seized and sustained. Most recently, this pursuit has seen researchers move to examine the organizational and management factors which contribute to peak performance (Fletcher \& Wagstaff, 2009; Wagstaff, Fletcher, \& Hanton, 2012a; Wagstaff, Hanton, \& Fletcher, 2013). While study in this budding area has primarily focused on holistic organizational functioning (incorporating strategic, policy, and administrative elements on top of traditional performance facets), it has concomitantly reinforced the significance of management-led processes within and for the principal gain of the performance department; including the Performance Director (hereafter PD) led creation and maintenance of a high performing culture (Fletcher \& Arnold, 2011). With limited knowledge on this particular process unearthed to date, work is therefore required through which PD-led culture change can be theoretically understood and practically delivered (cf. Fletcher \& Arnold, 2011).

Corresponding to "the shared values, beliefs, expectations, and practices across the members and generations of a defined group" (Cruickshank \& Collins, 2012a, p. 340), sport psychologists have long been aware of culture's role in shaping team and individual behavior and performance (Hardy \& Crace, 1997; Krane \& Baird, 2005; Lee, Shaw, \& Chesterfield, 2009), and increasingly so in Olympic environments (Fletcher \& Arnold, 2011; Wagstaff et al., 2012a). Indeed, the need for Olympic sports teams to operate in a setting which consistently enables peak performance and protects members (i.e., performers, support staff, and team management) from wider organizational distractions (e.g., internal politics: Arnold, Fletcher, \& Molyneux, 2012; Wagstaff et al., 2012a) has arguably never been greater. 
Specifically, with many funding agencies adopting a "no compromise", outcome-based approach to resource allocation (e.g., UK Sport ${ }^{1}$ : Sam, 2012), and national governing bodies undertaking detailed cross-examinations when objective success is not forthcoming (e.g., Magnay, 2013), most PDs are afforded little mercy for failing to establish systems which instantly and consistently deliver medals. Theoretically, and as sport psychologists possess greater scope for impact when working at inter- rather than intra-group levels (as intervention can reach and impact a wider number of groups and individuals), a focus on the culture of performance departments and, more precisely, how it may be changed also aligns with the field's recent gravitation toward performance leadership and constructs which function at higher levels of social aggregation (Arnold et al., 2012; Fletcher \& Arnold, 2011; Fletcher \& Wagstaff, 2009). Importantly, and despite the preference of business-based scholars to prioritize and assess the culture of entire organizations (Gilmore, 2013), this team-level orientation is firmly fixed to the pragmatics of both the PD and sport psychologist role (Cruickshank, Collins, \& Minten, 2013b; Fletcher \& Arnold, 2011).

Offering initial insight into Olympic PDs' creation and regulation of high performing team cultures, Fletcher and Arnold (2011) recently reported that establishing role awareness (including: PD awareness; developing colleague role knowledge) and creating an organizational and team atmosphere (including: creating an identity; improving quality and quantity of contact time; promoting compatibility behaviors) were key elements of optimal delivery. Presumably due to their obligatory broad focus (to offer the first overview of best practice across the entire PD role), Fletcher and Arnold concluded their study by calling for future work to "develop interventions that focus on how leaders and managers create, optimize and maintain a high performance environment" and breed "more lucid, evidencebased recommendations" (p. 237). Certainly, acknowledging that "time must be an essential

\footnotetext{
${ }^{1}$ UK Sport is the UK's high performance sport agency, responsible for allocating public funding and providing performance support to targeted sports (i.e., those most likely to deliver Olympic and Paralympic medals).
} 
part of investigations of change if processes are to be uncovered" (Pettigrew, Woodman, \& Cameron, 2001, p. 697), optimal theoretical and applied advances will logically require greater sensitivity to the when, why, and how of Olympic team culture change.

A second key consideration for continued Olympic team culture change study is what specific change episode to focus on. Indeed, as culture change involves creating shared and department-regulated values, beliefs, expectations, and practices which endure over time and promote consistent high performance (Cruickshank \& Collins, 2012a), a number of contextually specific "trigger events" could be investigated; for example, among others, the beginning of a new Olympic cycle, major increases/decreases in funding, or targeting medals in different disciplines. Given the pressure on PDs to "get it right first time" (cf. Sam, 2012), one event of particular interest is PD succession. Explicitly, as influential, incoming leaders inevitably redefine a group's strategy and contexts (Hutzschenreuter, Kleindienst, \& Greger, 2012), and are further expected to deliver a change of some kind (to either maintain or, more likely, improve on results achieved by their predecessor in a continually evolving setting), the extent to which the newly appointed PD can negotiate the anxiety-shaped dynamics of leader succession will be a key determinant of their program's short and long term success. Given its clear applied relevance, and taking sport psychology as an applied science, this process is therefore also of theoretical interest. Notably, the merit of conceptual understanding in crossindividual change activities within (parts of and whole) sport organizations has already been discussed in detail (cf. Cruickshank \& Collins, 2012b; Wagstaff, Fletcher, \& Hanton, 2012b). While incoming PD-led culture change within Olympic sport performance teams has not been examined in sufficient depth thus far, early linked work has been conducted in other areas; that is, in college (Schroeder, 2010) and professional (Cruickshank, Collins, \& Minten, 2013a) sports teams. However, although this latter study provided the first understanding of team management-led culture change in an elite sport environment, its primary focus lay with 
the interpretations and responses of key stakeholders rather than the generation of a model on which future study and practice could be based. Additionally, while Schroeder (2010) assumed a leader-oriented perspective to explore the culture change programs of successful NCAA head coaches, this research is also limited for informing Olympic PD-led culture change due to the significant contextual differences between college and Olympic sport settings. Moreover, Schroeder's work was undertaken and analyzed though Schein's (2004) model of organizational culture change; involving a linear, three step method of unfreezing, cognitive restructuring, and refreezing. Problematically, and supporting criticism of the organizational field's primarily abstract and decontextualized approach to culture change/change management inquiry and lack of sound practice theory (cf. Cruickshank \& Collins, 2012b; du Gay \& Vikkelsø, 2012; Sorge \& van Witteloostuijn, 2004; Van de Ven \& Sun, 2011), Schein's model could not fully explain the sport-specific process studied by Schroeder. As such, while sport psychology has profited from applying organizational-based knowledge to study organizational-based phenomena in sport (e.g., Wagstaff et al., 2012a), sports performance-based culture change research appears to require an approach which is sensitive to the unique features of performance sport ${ }^{2}$.

Reflecting on these identified needs, the purpose of this study was to develop a first grounded theory of incoming PD-led culture change in Olympic sport performance teams as perceived by those who have undertaken this crucial activity. Designed to unearth the process and nature of optimal practice from the perspective of the Olympic PD, findings will provide sport psychologists with a first conceptual understanding of this critical process and a framework on which their applied practice can be based. Additionally, insights will also

\footnotetext{
${ }^{2}$ For further contextualization of this point, the interested reader is directed to recent critical debate in this evolving and potentially powerful domain (see Cruickshank \& Collins, 2013; Cruickshank, Collins, \& Minten, 2013; Gilmore, 2013; Rynne, 2013).
} 
inform continued study in the elite sport organization domain and help to further define the relationship between performance team-specific and wider organizational matters.

\section{Method}

\section{Pragmatic Research Philosophy}

Identified as an approach by which organizational change could recover its "lost specificity" (du Gay \& Vikkelsø, 2012) and performance sport-specific study could profit (Cruickshank et al., 2013), the pragmatic research philosophy specifies that academic inquiry in an applied discipline should "make a difference" to the individuals or groups which it examines (Corbin \& Strauss, 2008; Giacobbi, Poczwardowski, \& Hager, 2005). Intended to bridge study and practice, research from this position therefore elucidates practical-level truths by developing understanding in how "real world" processes function in applied contexts rather than providing a definitive representation of "reality" or "realities". In this way, the products of a study are at all times provisional and specific to the contexts in which they were developed (Corbin \& Strauss, 2008).

Distinct from approaches which prioritize ontological and epistemological issues over methodological matters, pragmatism instead primarily directs scholars' focus toward research questions and the methods by which greatest applied impact can be conferred (Bryant, 2009). Crucially, however, pragmatism does not blindly ignore metaphysical concerns. Indeed, the position discards the foundational/positivist assumptions of an objective reality and that one interpretation can be said to more accurately represent "the truth" than others (Bryant, 2009; Giacobbi et al., 2005; Morgan, 2007). Accordingly, and although not forcing adherence to any one non-foundational belief system, pragmatism maintains that the interactions, biases, and prejudices of researchers are inevitable and, in fact, a vital source for abduction (i.e., innovative theorizing: Bryant, 2009). In this manner, pragmatists view knowledge as coconstructed between researchers and participants but (and avoiding the limits of an extreme 
relativism where no interpretation can be deemed more accurate than another) also see these constructions as corresponding to tangible applied artifacts (Corbin \& Strauss, 2008).

\section{Grounded Theory Methodology}

Useful for applied fields and questions focusing "on some kind of social process and how it operates within particular contextual conditions" (Holt \& Tamminen, 2010, p. 420), grounded theory was originally created as a method to occupy the pragmatic "middle ground" between extreme empiricism and relativism (Suddaby, 2006, p. 634). Although different versions of this approach have been developed under different philosophical positions for different purposes (for an overview, see Bryant, 2009), Corbin and Strauss' (2008) method was employed in this specific study due to its pragmatic philosophical foundations (cf. Corbin \& Strauss, pp. vii-17). Importantly, as this work aimed to develop a theory which was neither speculative nor universal but a transient and fallible tool for a particular context (i.e., substantive theory), this choice also met Pettigrew et al.'s (2001, p. 697) claim that "theories of change ... must face the double hurdle of scholarly quality and practical relevance."

\section{Sampling and Participants}

As grounded theory requires an iterative research process, in which there is a repeated interaction between data collection and analyses, theoretical sampling was employed (Corbin $\&$ Strauss, 2008). Adhering to our aim to generate substantive theory, contextual specificity was sustained by sampling individuals who had held a PD position in a British Olympic sport in the last two Olympic cycles (2004-2012). Due to the need to consider diverse perspectives (cf. Corbin \& Strauss, 2008), no parameters were set regarding the type of sport which these figures had overseen (i.e., individual, team, or individual plus team sport) or objective medal success (although statistics on the latter did support selection decisions). Rather, the research was engaged with a broad intention to work toward a final sample which had: (a) experienced varying degrees of success (i.e., short- and long-term role survival); (b) overseen sports with 
varying public profiles; and (c) overseen sports which had received varying levels of public funding. In this way, the credibility of our later assertions on culture change "best practice" could be optimized. Institutional ethics approval was obtained to sample on these grounds.

The full sampling and data collection process occurred over four phases. At first, two PDs were purposively sampled who had led change in individual plus team sports (i.e., sports which competed in both individual and team events at the Olympics). Driven by our analysis of data from this initial sample, in particular the significant constraints placed on PDs by their Boards and UK Sport, it was determined that a second sample would focus on PDs who had faced difficulties in dealing with top management and this external funding agency (one from an individual sport; one from a team sport); as directed by an informed former PD. Guided by results which pointed to the amplification of these challenges (and others) in the lead up to an impending home Games, the third sampling phase targeted two PDs (both individual plus team sport) who currently worked in multi-discipline (and thereby politically more complex) sports. With the only novel finding from this sample being the extent to which PDs must manage the media's expectations and interactions, one PD from a high profile sport with high public scrutiny was recruited as the final sample. As the data from this PD provided unique perspectives on previously identified concepts and categories but no fundamentally distinct insights, saturation was deemed to have been achieved at this point (Corbin \& Strauss, 2008).

The overall sample included seven PDs: five had led programs in individual plus team sports; one in an individual sport; and one in a team sport. All interviewees were male, aged between 47 and 59 years $(M=53.00, S D=4.28)$, had held PD roles for 68 years in total $(M=$ 9.71, $S D=6.26$ ), and had led teams to a collective total of 33 Olympic medals. The shortest and longest tenures as PD were 4 and 21 years respectively, with a mean tenure of 7.56 years $(S D=3.63)$. Four participants were employed in a PD role at the time of their interview.

\section{Data Collection}


As shaped by the study's practical constraints - specifically, the limited access to high profile and time-pressured participants - one-shot, semi-structured interviews were used to collect data (cf. Buchanan \& Bryman, 2007). Prior to meeting with the main participants, the focus, content, and clarity of an initial interview guide was piloted with three elite sport performance team managers; a process which emphasized a number of apparently significant culture change tasks (e.g., initial interactions with the Board, developing relationships with key staff). While the core questions of the guide were not altered by this pilot work, followup probes were modified to allow for detailed discussion on these particular factors with the main participant pool.

Interviews with the main participant pool focused on seven open-ended questions. As required to advance Fletcher and Arnold's (2011) opening findings on PD-led culture change, alongside the need to ensure that each interview addressed the full topic in the afforded time, these questions followed a chronological order and covered: program goals; pre-change steps; processes and actions for initiating change; processes and actions for sustaining change; key qualities and skills for carrying out change; evaluation processes and actions; and reflections on success and/or failure. Significantly, this general structure did not constrain interviewees' responses with issues explored as they were presented in an essentially organic conversation. All interviews were conducted at locations chosen by the participants and lasted between 110 and 165 minutes. Confidentiality was assured and all participants provided informed consent.

\section{Data Analysis}

Verbatim transcripts were analyzed using qualitative analysis software (QSR NVIVO 9). Initially, concepts were identified via an open coding procedure (Strauss \& Corbin, 1998) and the constant comparison method (data to: data, codes, concepts, literature) used to enable the creation of distinct conceptual categories with defined properties and dimensions. Axial coding was then employed to develop these discovered concepts and illuminate category and 
subcategory relationships; a process which fueled our theoretical sampling when it was found that categories required further saturation. Importantly, when interviews had to be conducted soon after each other, an iterative process was upheld by detailed note-taking, memo writing, listening back to the last interview, and critical discussion between ourselves. Presenting our developing findings at conferences also supported this recursive data collection and analysis process (cf. Holt \& Tamminen, 2010).

To uncover a central process and refine the developing theory, theoretical integration was enabled by memo writing - in terms of the evolving concept and category relationships and by drawing diagrams of possible models early in the research process (Corbin \& Strauss, 2008). In the last phase of the research process, concepts and categories were also contrasted and integrated with extant theories and constructs; a process supported by a deferred second review of the literature (Strauss \& Corbin, 1998).

\section{Results}

To illuminate incoming PD-led culture change best practice in British Olympic sport performance teams, the process' chief components are presented first. As shown in Figure 1, efficient and effective change involved PDs' execution of two linked yet conceptually distinct activities. Expressly, when appointed into a role, best practice relied on an initial evaluation, planning, and impact phase affixed to the instant and enduring management of a holistic, integrated, and dynamic social system. With both of these facets co-initiated and codependent, the initial evaluation, planning, and impact period acted as the program catalyst, providing a platform upon which long-term change could be optimally delivered. A description of this opening process is now presented before elucidating the elements of the main social system second. The results section then concludes by explaining the theoretical links between these chief components in the developed grounded theory model. To clarify, these findings represent an amalgamation of interviewees' successfully deployed approaches, 
views on best practice, and reflections on past mistakes. PDs identified by PD1, PD2, PD5, PD6, and PD7 had led individual plus team sports, PD3 a team sport, and PD4 an individual sport.

\section{Initial Evaluation, Planning, and Impact}

Gaining an understanding of the cultural, political, and performance landscape.

Based on the scale of the challenge and the need to deliver a contextually-specific program, interviewees reported that gaining an understanding of their sport's cultural, political, and performance landscape was a critical initial activity. For example, information was particularly sought on: the relationship between the governing body, the governing body's performance arm, and UK Sport; the abilities and potential of "upper echelon" team management/support staff and senior-/development-level performers; and the wider social milieu and its "key players". Certainly, resonating with advice that PDs should generally “identify what needs to be delivered" (Arnold et al., 2012, p. 323), our interviewees discussed how their opening analysis formed the bedrock on which their short-, medium-, and longterm goals could be set and attainment strategies designed. Invariably, the evaluation of a sport's history, traditions, resources, competitive contexts, governance/staff networks, and relationship with key external agencies (e.g., UK Sport, $\mathrm{BOA}^{3}$ ) required the PD to source and assimilate views from both inside and outside of the performance department:

I talked to . . . [support] staff, people working within the governing body, committee members. I spent a lot of time ... talking to coaches ... [and] partners of the governing body; I talked to people about their perceptions of [sport] . . . I did a lot of background work on the person who would be my boss as well, as to how amenable they would be to change ... [and] how much freedom I would have to make decisions. That was a process ... that stood me in pretty good stead. (PD1)

\footnotetext{
${ }^{3}$ BOA stands for British Olympic Association; this body is the UK's National Olympic Association with a responsibility for the selection and conduct of British teams at the Olympic Games.
} 
Suggesting that instantly speaking to a variety of stakeholders was optimally informative and politically sensible, this quote also clearly emphasizes the significance of PDs developing an understanding of their own manager's personality and work style. Indeed, given the known need for PD-top management coherency (Arnold et al., 2012), one PD further described the problems of not possessing a precise awareness of the sport's internal management structures: It was clear [after my appointment] that [parallel director] ... wanted me to report to [him/her] . . . I I think [his/her] famous quote was: "I'm not quite ready to let you off the leash yet" ... That was about three months into the job, and I just went - "this is crazy." I didn't know what he/she did except that I paid for part of his/her salary . . . [and] that he/she stuck her nose in wherever he/she wanted. (PD7)

As such, beyond sourcing "hard" information (e.g., funding allocations, facilities, the scale and spread of staff, equipment, current performance systems, structures, and processes), the PD's optimal initial analysis was portrayed as a particularly tactical process, with specific individuals targeted for early, positive interactions based on their structural or social position. Engaged to swiftly enhance their actual or perceived political sensitivity, such action was vital for easing the transition into a role and garnering support (or minimizing dissent) from those with sufficient power to manipulate the program's delivery and outcomes; a point extended in the following concept.

\section{Identifying, recruiting, and harnessing multi-domain experts, allies, and cultural}

architects. Due the uncertainty and/or skepticism which surrounded many PDs at the time of their appointment, and at times overt disapproval (especially in sports where the role had not previously existed), best practice also relied upon the concurrent facilitation of personal and program support from multiple experts (e.g., Heads of Science and Medicine, head coaches) and influential actors who could then act as social allies and cultural architects (Railo, 1986). In this way, the creation of management structures and a guiding coalition (or "war cabinet": 
PD3) which was consistent with the desired culture was a key marker of instant and enduring success. Vitally, and rather than "passively" facilitating the intended culture via adherence to the PD's espoused values and standards, such experts, allies, and architects were also utilized to actively construct the values, perceptions, and practices of the staff which they oversaw: I used performance management [to help deliver changes] . . . because I couldn't rely on [dissenting] coaches ... I had to have some central means of people looking down [and] ... keeping an eye on [coaches] ... . I used the term: asking the hard questions and requiring the hard answers. So [performance managers would ask:] "what are you doing with your athlete? Where are you going? What's the plan? How does it work?" They [performance managers] were, if you like, my agents of change. (PD7) Interestingly, allies and cultural architects at coach/athlete levels were not always current top performers or those based at historically successful locations. Indeed, and emphasizing how short-term action was optimally delivered against long-term agendas, one PD described how they targeted a performer and coach who were "bubbling up" within their system:

Finding a future potential world champion and their coach ... [is] very influential because you can make some noise around them. . . [The potential champion] was significantly disenfranchised ... prior to my arrival .... [But] he was going to be the team leader for some years to come and so making him know that the program was about him, not that he was second fiddle, was very important. (PD4)

Outside the performance department, and beyond the aforementioned need to understand the personality and working style of top management, PDs also acknowledged the significance of actively facilitating and sustaining support from their Board and CEO:

Making sure you are covered [with your CEO] would be a career lesson for me. . . Because if they're not with you then they'll pull the rug out when a big call's needed . ... You [need to] have a strong and trusting relationship because ultimately it's [top 
management's] direction, they have the power .... If you want to take something in a direction they don't want to go they've got the influence to stop you. (PD4)

Finally, and reflecting their ability to shape both internal and external stakeholder perception, rapidly acquiring allies and cultural architects within the media was also revealed to be a key success factor; particularly for dampening opportunities for early criticism:

I flew to [major event shortly after appointment] ... . [It was] like waiting for a car crash .... I knew we were weak ... and I had to sit there knowing this was coming but ... not be able to do anything .... [We underperformed] and I had to . . explain [to the media] why ... and say: “you're absolutely right, it's not good enough". [The media said:] "You agree?" "Of course it's not good enough, it must change". (PD7)

Indeed, even when fortunate to oversee initially successful results, another PD stated that: "it was very good to have journalists on-side because ... when the shit does [inevitably] start hitting the fan you can speak to [them] ... . They will write about you with respect. (PD4)

Facilitating shared perceptions and multi-stakeholder support. Beyond seeking support from structurally and socially influential actors, and operationalizing Arnold et al.'s (2012, p. 323) advice for PDs to "set expectations" and "integrate and engage all areas of the [national governing body]", our participants also discussed the need to promote awareness of their program's focus and aims across all corners of their sport's social environment. For instance, sharing pertinent (yet filtered) information with the governing body board(s), UK Sport, the BOA, external partners (e.g., Institutes of Sport), support staff, performers, and the wider sport membership (e.g., recreational coaches/performers)increased the likelihood of a PD's program being positively received and therefore usefully propagated by those "inside" and on the periphery of the performance department. Within the department, engaging all upper echelon staff in program design was considered particularly valuable: 
It's about ... trying to get [upper echelon staff] all in the same place so they can start to be really creative [about the vision]; they are not coming in just thinking about the here and now .... So that when you've [devised a plan], it's theirs . . . It's not about me ... They're meeting all these volunteers . . . . If you are trying to shift a culture you have got to get your people to buy into what it is you are trying to do. (PD5) From an "external" perspective, and due to the "noise" which they could create in and around the performance department, facilitating positive first impressions with the governing body board(s) and a sport's sub-disciplines (where prevalent) was also particularly impactful: I used to go to the [ $n$ disciplines'] committee meetings . . . . I'd be there for a whole day and sit through the $\mathrm{A}$ to $\mathrm{Z}$ of the whole discipline, but ... I'd be engaging and interested and understanding, trying to see what was common for all . . . and I think that meant quite a lot to people .... You just try and take people with you. (PD5) Interestingly, generating multi-stakeholder support was not always addressed through overt action and dialogue. For example, symbolic actions could also foster collective buy-in: Some [impression management activities] . . come through as a demonstration; it could be as simple as the next time [that the performers] go on a training camp the quality of that training camp is higher than what they've seen before. "Wow this is professional! Oh my god, we're doing some good stuff here, look at this!” (PD4). Similarly, who the PD chose not to speak to during the opening period of their tenure could also "subliminally" create shared expectations over the focus and principles of their program: A problem for me ... at the start ... [was that] I was having to 'manage upwards' ridiculously ... . [Additionally, lower echelon support staff] didn't want to talk to the performance managers, they want to talk to me; why talk to the monkey when you can talk to the organ grinder? So to an extent I deliberately wasn't there [to encourage adherence to the new performance management and reporting structure]. (PD7) 
Prioritizing and addressing most pressing needs. As well as optimizing social and political support (and minimizing detrimental conflict), PDs also revealed the importance of instantly addressing the performance department's most pressing system-, structure-, process, and climate-based needs; often involving an early reorganization of internal staffing:

I was pretty dissatisfied with ... [the support staff] . . because we're not pushing any boundaries .... There was a physio went .... I brought somebody in over the top of [sport scientists] and gave them liberty to run some exciting stuff .... It was a pretty quick process .... There was a little bit of pain - “oh they're people we've worked with for a while" - [but] that was a [necessary] step change; we just changed it. (PD4) Notably, the need to address political matters was also raised; particularly the relationship between PD, their sport's governing body, and UK Sport. Certainly, due to the disruption which top-management/external conflicts could have on team performance, ironing out any political differences was a crucial early activity for most PDs:

I picked up very quickly when I got here that [the] World Class [program] wasn't wonderfully popular amongst the [governing body and its sub-disciplines] and the bridges had been broken so it was a matter of rebuilding that communication. (PD6)

Withholding initial action in sub-optimal conditions. As well as targeting areas for immediate improvement, participants also conversely discussed the need to refrain from (or delay) some initial activities due to the negative response that they would likely elicit.

Described by many as "picking your battles", and resonating with results from Wagstaff et al. (2012a), sensitivity to stakeholders' perceptions, opinions, and power alongside an awareness of "the bigger picture" lay at the heart of best practice in this area: 
I would recognize the volume of challenge and I'd choose my battles . . . I can do something about $[\mathrm{X}]$, I can have a win here; but there's not much I can do about $[\mathrm{Y}]$. . . unless I get rid of that bloke, or unless we change this... (PD7)

Beyond actively avoiding some inevitably damaging (or conflict-perpetuating) situations, another PD interestingly described the need for interpersonally- and politically-sensitive "onthe-spot" decision making to support attainment of their long-term goals:

When you raise something [to a stakeholder], you might think it's very important but you are gauging what that first response is .... If they really kick against it, I'll probably put it back in my pocket .... I probably still know that we need to go there but what I'm going to find is a different way of going there. (PD4)

Facilitating optimal immediate results. Tying in with all of the above themes, PDs also discussed the significance of enabling optimal immediate results; particularly those who were appointed shortly before a major event:

When I arrived ... [Olympic Games] was only $[n]$ months away and it was very clear that basic logistic details hadn't been finalized ... . So aim one was [Olympics] - that had to be the focus for the first few months. I said to the person ... running the development program: “not interested!” (PD6)

Significantly, and although most interviewees worked toward achieving consistent results in the long term, it was commonly perceived that instant success did (or could) encourage a speedier acceptance of, and a greater thrust behind their fledgling programs:

At almost exactly the same ... time as [appointing new performance managers] we had the best [major event] we had ever had .... While the two issues were probably relatively unrelated, [it helped that] ... performances were improved at that same time as we were making change. That almost was a green light to continue. (PD1) 
Indeed, optimizing the potential for instant positive results was found to give the PD "a much stronger hand ... [particularly] if there are a lot of question marks" (PD3).

\section{Management of a Holistic, Integrated, and Dynamic Social System}

The second and most substantial element of optimal incoming PD-led culture change was the management of a holistic, integrated, and dynamic social system. Built on a two-way interaction and power flow with internal and external stakeholders (the components of which were discovered to be managing multi-stakeholder perceptions and expectations and actionguiding multi-stakeholder perceptions and actions; see Figure 1), exemplars of this process are now provided for each identified relationship.

\section{Two-way interaction and power flow with upper echelon team management and}

support staff. As recognized by all PDs, creating and sustaining an empowered and "on message" staff at the upper echelons of the performance department was a key culture change success factor; especially as the self-interests of staff (propagated by the need to protect their own position in an environment where performance feedback is sporadic) often posed one of the greatest culture change challenges. To overcome the potentially destructive interaction of staff self-preservation, all PDs advocated a two-way, teamwork-based approach:

[I adopted a] a very inclusive management style [and would sit with the performance managers and ask]: "how are we going to do this? The outcomes [i.e., UK Sport medal targets] are non-negotiable ... . [but] where there is wriggle room is how we are going to do it. I'm thinking we might do this, what do you think?' Then you would solicit input and when people stopped being defensive ... [and] realized that . . . I was willing to listen ... [they said] "that's great, let's do this". So [my primary approach was based on] soliciting their ideas and building on their ideas. (PD7) 
With another PD stating that "if you are trying to do it just on your own it will . . fall apart" (PD2), and recognizing the power which upper echelon staff held (through structural position and/or personality), opportunities were often sought to reach negotiated agreements:

It was a two-way decision [to redefine the role of the influential national coach]: he wanted to move [geographically] ... and we wanted to try some different stuff and it seemed to fit. I was very happy to go along with it because I [also wanted] . . . [him/her to] to be flourishing. . . [and] give... what's beyond the norm. (PD4)

Two-way interaction and power flow with lower echelon support staff. Akin to the preceding concept, two-way interactions with lower echelon support staff were also deemed vital for creating and sustaining a high performing culture. Notably, collaborative communication and a continuous flow of power were also facilitated within this particular staffing group:

To help [performer] we brought in a [foreign nation] coach . . but I made it clear [to them] that ... . [home nation] coach is totally in charge: "you are 'adding value'." It might do nothing but reinforce [performer's established coach] in what he/she's doing but sometimes it's really important for a coach to have another one next to him/her saying, "this is good, or you need to add this." So we saw it as a support mechanism to the coach and that's been a real success story. (PD2)

Revealing how interactions with support staff were not always positive or smooth processes, however, another PD revealed the need to remain firm in one's negotiating stance when staff "overstepped the mark" in providing their perceptions and opinions:

[Lower echelon coach] kept shouting down the phone: "[you've] got no respect for me, and I can do this, and I can do that, and I can do the other, and you should pay me this much" ... "Whoa, whoa, whoa, you're not qualified man, you know you have 
no record. Show me you can do it and I will fund you but I am not funding you now; I haven't got the ability to take flyers on people as coaches". (PD7)

Two-way interaction and power flow with performers. Given their status as the group on which the outcomes of change were primarily focused, building and sustaining twoway relationships with performers was pivotal for both immediate and enduring success. However, with most sports only able to select a relatively small number to compete at the Olympics, conflict and tension was a common factor; even rising to the extreme level of personal threats. As such, top-down direction was rarely workable or effective:

Some of the top athletes ... have been doing [sport] for over [x] years [so] you don't just walk in and go: "right you are doing this, this and this now"; they would just tell you to $* * * *$ off! (PD6)

Accordingly, it was imperative that PDs (either directly or via established channels) provided a continuous stream of information on pertinent actions and decisions which respected athlete performance and general well-being, as well as optimizing role clarity (e.g., selection and funding standards) and providing a "managed" level of ownership:

I think [performers] have to have a voice .... Whether you ultimately listen to that voice [is a different matter] but I think [performers] have to have a voice. They have to feel they have a voice, so that's two-way communications if you like. So creating things like athlete representation, creating the situations where it is about them. (PD4) As intriguingly suggested by this excerpt, PDs' interactions with performers were not always entirely or authentically "two-way". Certainly, as pressure from Boards and UK Sport meant that PDs had limited scope to deliver compromised and innovative approaches to performerrelevant systems and processes, interviewees therefore often worked to create the perception of a reciprocal relationship to best sustain program direction and momentum; a finding which 
further supports the prevalence and utility of dark side traits (in this case, Machiavellianism) in successfully leading Olympic sport performance teams (Fletcher \& Arnold, 2011).

Two-way interaction and power flow with the governing body board(s). Due to the power held by the governing body board(s), PDs also reported the importance of two-way relationships with those who oversaw the sport's ultimate direction. Notably, the challenges of engaging in such a process were particularly pertinent in the lead up to the London Games:

When we went to [a 2010 practice event], I got back and one of the chief execs said to me: "I haven’t seen you around recently". "You know, [practice] event?!" "Oh, was it?” This year they're all [asking] ... . “what's our role at [practice event]; we haven't got a role ... but there are British people [competing] and we're the chief executives of British [sport]!”. Well who gives a ****, you know! (PD6)

Resonating with earlier points, the PD's relationship with their sport's $\mathrm{CEO}(\mathrm{s})$ was crucial for preventing interference from the wider organization impacting on performance, with optimal benefits found from establishing and sustaining a steady "to and fro" communication channel. Indeed, one PD recounted that the CEO-enforced cessation of such two-way interactions was a particularly significant marker in their program's eventual termination:

[I managed] upwards went quite well until [the appointment of a new CEO] and then I was excluded from the Board ... . The excuse was: “oh, you've got too many other things to do." But it was really [that they were planning to recruit a new PD]! I should have at the time insisted [on staying involved in Board meetings]. (PD7)

Two-way interaction and power flow with UK Sport. As the principal funder of British Olympic spot performance programs, effective two-way interactions between PD and UK Sport were considered imperative for enduring success. Although many interviewees were critical of UK's Sport evolution toward becoming more "a bank manager" than support agency (PD4), as well as their naïve desire "for us [all] to have this big system . . like 
cycling" (PD7), the need to respect this group's power was fundamental for culture change best practice:

[At] Athens we had $n$ finalists, [at] Beijing we had [>n]; that's a massive change ... [However] the first comment ... [from our UK Sport Representative] was :“Oh, you didn't get a medal” ... . It wasn't 'til I shoved [a table of comparisons] up his nose he suddenly went: “Geez, you've done pretty good” . . . It's very important to just keep everything in perspective and not always measure it on the outcome. That's why it's not called outcome director! The day it is I won't be turning up. (PD2)

In this manner, two-way interaction with UK Sport was a highly political process, with PDs proactively conveying alignment with the agency's principles and practices, educating their representative(s) on the nuances of their sport, explaining and justifying actions and decision making, promoting performance successes, and integrating representatives in work and social activities. Indeed, rather than the more transparent relationships PDs sought with their upper echelon support staff, interactions with UK Sport were fundamentally more guarded:

You are conscious that they are your funder so you are playing a little bit of a game to make sure that you get your money .... We're not really going to tell you the weaknesses; we are going to tell you the things we can improve. (PD4)

Two-way interaction and power flow with the British Olympic Association. As the body responsible for selecting, organizing and delivering Team GB at an Olympic Games, a reciprocal relationship was also required with the BOA. Similar to the need to proactively acquire and sustain the support of UK Sport, the impact of not having a two-way relationship with the BOA often only came to light at times of major significance:

We had a ... critical catastrophe where ... a [top] athlete who was coming back from injury didn't race in ... [Olympic] selection race [and] I had the conversation [that they couldn't be selected] . . . and there were tears and whatever. When I phoned the . 
.. BOA to say "here's where we are, I need you to make that change", they wouldn't do it. Then you go: "oh shit" .. . "You are stopping me delivering on what I've said and what I've said is not contrary to ... any over-riding rule" ... . Then I'm a lame duck and I might as well walk out now. Actually I probably should have done. (PD4) Two-way interaction and power flow with external partners. With peak athletic performance reliant on the PD's ability to source, harness, and develop all available resources and support mechanisms, a two-way interaction and power flow with a variety of external partners was further reported; most notably, the UK's national Institutes of Sport. Certainly, while the PD held particular power as "the customer", rapidly creating and sustaining shared expectations was an invaluable strategy for facilitating a tailored, committed and empowered medical/sport science service:

When you go in [to the Institute] somebody explains that this is the services that we supply and my first question is - "do I have to use the people here? I might want to . . . get somebody [different] on the technology side ... That's a difficult question for them because they've got people employed, they've got a network and ... I went in and we had a good chat about things. (PD3)

For another PD, the need to effectively respect, engage with, and respond to key partners who provided fundamental resources but received no financial reimbursement meant that specific attention had to be directed toward the quality of their interpersonal relationship:

It's about creating that environment where people want to be part of Team GB. Now, whether that's giving [external partners] free clothing ... or taking them out to dinner occasionally, or giving them montages of [supported performance successes], that's our life. It's all about creating this environment where people want to be part of the team. You can't force them. (PD6) 
Two-way interaction and power flow with the media. Although a greater concern for the PDs of higher profile sports, the challenge of media power and influence - particularly ahead of a home Games - was also emphasized as an important component in establishing and maintaining a high performing team culture. Acknowledging that the media could not be simply ignored (albeit they were often a significant distraction for all members of the performance department), PDs discussed the benefits of proactively addressing this group's needs (within limits) by offering a level of quality access:

We've very much changed our approach ... to be a lot more engaging with the media At recent [event] we ran a media day and ... . it allowed us to build up relationships with journalists so I think we have a lot of people who are on our side now . . . . Ultimately we want ... greater exposure, we want more members into the sport ... and to give the sport a legacy as well. (PD1)

As illuminated by this PD, the merit of engaging with the media and developing a useful twoway relationship was not primarily in optimizing the perceptions of specific journalists or reporters per se. Rather, and reflecting the geographical, operational, and political challenges which characterized many sports, the ability to send messages through the media to targeted individuals and groups was a particularly effective culture change mechanism:

The written media got better . . . as I stopped answering questions and started using them, and it got better as I got a good press officer .... [The press officer] was a means to send messages up, out and down, at the same time as it was a means to stop [the media] shooting because there was a very vociferous and negative press. (PD7) Two-way interaction and power flow with other significant influences. As each team operated in its own unique contexts (as shaped by its distinctive history, traditions, and resources), an array of other significant external groups shaped the PD-led culture change process; most commonly, a sport's wider (i.e., non-performance) membership, influential ex- 
performers/coaches, and (an outcome-focused) general public. Although these groups did not carry the same level of influence as others (e.g., UK Sport, the BOA, the media), the social complexity of the performance department (as governed by the dynamic interactions of variously-motivated stakeholders) meant that their perceptions and actions could nonetheless trigger eventual critical shifts in team culture. For instance, one PD discussed how they used internal media channels to optimize the perceptions of the sport's wider membership:

We have an internal magazine [sent to the whole membership] and ... I've written a couple of articles in there ... explaining myself, my background, and what my role is .... It's just getting the message across . . . because there is always the dilemma in Olympic sport that ... you spend a lot of cash on a very small group, and I suppose you do have to go through the process of making some justification for that; particularly as it's either public money ... or membership money. (PD1)

Additionally, being politically savvy over the impact of decisions and actions on those who had interests in performer training (e.g., owners/sponsors of specific training facilities/events) was highlighted by another PD as a particularly pertinent task:

[I was] very, very, overt [with] "this is why we are doing what we are doing" to everybody; to [influential ex-performer] . . . to [influential ex-performer] . . . to [influential ex-performer] . . . But [my conversations were] always starting with: “look, you've been very good - what do you think?" (PD7).

\section{A Grounded Theory: Incoming PD-led Culture Change in British Olympic Sport}

\section{Performance Teams}

The grounded theory of optimal PD-led culture change in British Olympic sport performance teams is shown in Figure 1. Initially, to ensure that a program was consistent with, sensitive to, and exploitative of historical, competitive, and social contexts, best practice was centered on an efficient acquisition and assimilation of information relating to a 
sport's cultural, political, and performance landscape. Reflecting the geographical, operational, and political challenges of leading a national sports team, and the interactions of many external agencies (e.g., governing body Boards, UK Sport, the BOA, external partners, wider membership, media), this evaluation period was paired with: identifying, recruiting, and harnessing multi-domain experts, allies, and cultural architects; and facilitating shared perceptions and broad stakeholder support. To further optimize internal and external respect, trust, and confidence in the impending program (and minimize the prevalence and impact of inevitable resistance or opposition), critical psychosocial momentum was also best achieved by addressing the sport's most pressing needs (i.e., delivering visible and positive change to widely-accepted shortcomings), withholding from initial action in sub-optimal conditions (i.e., "picking your battles"), and facilitating optimal immediate results.

Regarding its main and enduring component (management of a holistic, dynamic, and integrated social system), the figure shows that culture change was reliant on establishing and upholding shared values, standards, and practices within the performance department through a two-way interaction and power flow with all implicated stakeholders. Importantly, similar relationships were also required with influential external stakeholders in order to: (a) protect the performance department's "cultural bubble" from external distractions; and (b) reinforce department-specific values, standards, and practices via the positive features of these groups' agency. Reflecting the nonlinear and negotiated nature of social interactions, optimal culture change therefore involved the continuous attainment, integration, and management of (a) the oscillating perceptions and opinions of team management, support staff, and performers, and (b) the oscillating perceptions and opinions of those who could indirectly strengthen or alter the developing and/or established team culture (i.e., governing body Board(s), UK Sport, the BOA, external partners, the media, other significant influences).

\section{General Discussion}


This study developed a first grounded theory of incoming PD-led culture change best practice in British Olympic sport performance teams. While initial evaluation, planning, and impact provided the foundation for effective change, the model conveys a principally holistic, integrated, and multi-directional process. Extending opening insights from Fletcher and Arnold (2011), as well as operationalizing some general PD competencies within a specific applied task (cf. Arnold et al., 2013), the power, agency, and interaction of internal and external stakeholders generated a framework which revolved around the constant acquisition, negotiation, and configuration of multi-stakeholder perceptions. In this way, the values, standards, and practices of the performance department were at all times sensitive to, and exploitative of macro (e.g., history, traditions), meso (e.g., profile, funding), and micro (e.g., stakeholder perception) contexts. Indeed, and echoing Schroeder (2010), creating and sustaining a high performing culture required a PD to relentlessly link all performance-based systems, structures, processes, actions, and discourses to the new and/or refined social norms.

Given sport psychologists recent use of organizational-based literature to inform their study of organizational-based phenomenon in elite sport (e.g., Wagstaff et al., 2012a, 2012b; Wagstaff et al., 2013), it is further pertinent to note that, in the specific case of PD-led culture change, the model generated by this paper contradicts the top-down, linear, and decontextualized nature of many organizational-based change models (cf. du Gay \& Vikkelsø, 2012; Cruickshank \& Collins, 2012b; Rynne, 2013). More specifically, while much organizational change theory has assumed and advocated a leader-centric approach (where success is derived from top-down leadership and followers' passivity), our model is embedded in multiple stakeholders' divergent motivations and thereby power- and politicalbased dynamics; features which have been largely overlooked in applied organizational-based prescription (cf. Tatlı \& Özbilgin, 2009). Additionally, with no distinct "end point", our framework also conveys an essentially boundless pursuit and not, as a number of 
organizational-based models suggest, a time-locked checklist-oriented activity which works toward an ultimate conclusion (cf. By, 2005; du Gay \& Vikkelsø, 2012).

As this study was also engaged with the aim to support advances in applied practice, it is important to consider the implications for psychologists and PDs as they seek to support or lead culture change programs. Evidently, as our grounded theory was jointly intended to be a practical tool (Corbin \& Strauss, 2008), its individual components are applied lessons in their own right; for example, when taking on the role PDs are advised to: gain an understanding of the sport's cultural political, and performance landscape; identify, recruit, and harness multidomain experts, allies, and cultural architects; facilitate shared perceptions and multistakeholder support; prioritize and address the sport's most pressing needs; withhold from initial action in sub-optimal conditions; and facilitate optimal immediate results. Beyond this guidance, perhaps the framework's most significant contribution is in its promotion of a 360degree, multi-stakeholder approach. Indeed, while sport psychology has historically assessed top-down (e.g., leadership) and bottom-up factors (e.g., coach-athlete relationships) in team settings, the findings of this research reveal that social change requires the principal change agent to manage and proactively manipulate all corners of their social setting - including sideways influences (e.g., external partners, media, other significant influences: cf. Figure 1). Again, awareness and consideration of these stakeholders' proximity, power, and divergent agendas should pervade all decision making processes, with individuals and groups highest on these dimensions targeted for particularly careful management throughout a PD's tenure.

Beyond this "multidirectional" perspective, a further key implication delivered by this grounded theory model is the importance of PDs' proactively facilitating a continuous to and fro of social power. By promoting a constant flow of information and interests between PD and those on which their program ultimately depends, this approach works to embrace social complexity and provides a crucial channel for stakeholders' perceptions and opinions to be 
productively and safely vented. Indeed, and echoing and building on Wagstaff et al. (2012a), providing frequent opportunities for all implicated stakeholders to "have their say" works to keep these groups “on-side” and, significantly, further supports the PD's status as a respected authority (crucial for times when top-down, directive leadership is required). Accordingly, it is in this way that PDs may best quell the politics, self-interest, and spiteful undertones of any Olympic sport performance department; or at least restrict these to quarters which do not carry the potential to trigger rapid and harmful shifts in social functioning (e.g., coaches or performers with limited potential).

To enable assessment of study quality, it is pertinent to consider this study's strengths and limitations. In terms of strengths, of initial note is the demonstration of methodological coherence (i.e., congruence across philosophical position, research question, participants, and methods; cf. Holt \& Tamminen, 2010). While the final sample size was comparatively small compared to some other grounded theories, a further strength was our attainment of saturation via significant access (interviews lasted over 2.5 hours on average) to high-level (and, to date, understudied) participants. Indeed, given the recent identification of contextual specificity as the condition for recovering the "lost specificity" of a hitherto positivist-dominated literature in organizational change management (cf. du Gay \& Vikkelsø, 2012), our focus on sourcing a depth of temporally-grounded, case-based data from interviews exploring full culture change programs (rather than eliciting a breadth of shallow data on parts of the process from a wider pool) heeds the most significant lesson from the culture change construct's parent field.

To assess the quality of findings, we direct the reader to consider Corbin and Strauss' (2008) specific criteria of: fit (i.e., do they fit the experiences of PDs?); applicability (i.e., do they present novel insights and extend practice?); concepts (i.e., are they structured around concepts and themes which enable shared knowledge?) contextualization of concepts (i.e., are they placed against Olympic sport-specific challenges?); logic (i.e., do they "make sense" and 
flow logically?); depth (i.e., do descriptions add richness?); variation (i.e., are negative cases included and complexity demonstrated?); creativity (i.e., are they inventive?); and sensitivity (i.e., are they derived from an analysis-driven process?). Sustaining a pragmatic philosophy, we also encourage the reader to apply the "so what?" principle (cf. Bryant, 2009); explicitly, what applied impact does the model confer if it does correspond to tangible applied artifacts? In this case, we note that future action-research oriented work is required but see merit in this being the first framework of incoming PD-led culture change in sport psychology literature.

Regarding shortcomings, the quality of the acquired data could have been weakened by the study's retrospective design and therefore hindsight and self-preservation biases; limits which may have been particularly prevalent with participants who were not currently in a PD role. In focusing on PDs within a British context only, the extent to which results could be used to guide future work and practice in other countries is also unknown. As such, future work should assess the presented model's relevance and efficacy across a variety of Olympic performance team settings. To develop our findings, focused assessment of the model's chief components should also be undertaken. For instance, the retrospective or real time tracking of incoming PDs' opening approaches against the activities detailed within the initial evaluation, planning, and impact phase of our model would work to corroborate, refine, and extend understanding of this crucial process. Reflecting its significance, specific work on the relationship between PD and top-management structures would also seem merited; especially as pressure from funding agencies can stifle long-term innovation (Sam, 2012). Additionally, as PDs commonly lead performers "one position removed" (i.e., with no direct responsibility for day-to-day training), research into how coherence is ensured between PD, upper echelon management and support staff, and lower echelon support staff will provide a further notable contribution to the literature. Similarly, moving to explore power dynamics between multiple stakeholders at multiple levels (e.g., performers, coaches, performance managers, UK Sport, 
Institutes of Sport, the media) at specific and contested moments of a change program would further elucidate the complexity of the PD's social setting and how this may be best managed through the application of both bright and dark side traits (Judge, Piccolo, \& Kosalka, 2009). Finally, scholars should also follow the lead of Wagstaff et al. (2013) and undertake actionresearch based inquiry. In the case of incoming PD-led culture change, a mixed methods approach (integrating multi-stakeholder perceptions and performance data) will allow for our model's key tenets to be tested and refined and further deepen our awareness of the dynamic and contested nature of culture change within Olympic sport performance teams.

To conclude, this paper has provided the first exploration of incoming PD-led culture change best practice in Olympic sport performance teams; in doing so, revealing an innately complex, contested, and multidirectional process. As well as working to constantly negotiate and reinforce the values, standards, and practices of those within the performance department itself, as underpinned by a number of critical initial activities, the developed model conveyed that optimal delivery was dependent on a PD continually protecting this cultural bubble from external interference. Moreover, this model also equips PDs and their supporting consultants with important heuristics on which to base their culture change-based decision making; most pertinently, a multi-directional orientation and the proactive, incessant, and consistent power share with all implicated stakeholders. Given the early stage of sports team-specific culture change investigation, and the apparent unsuitability of current organizational-based models, these results offer an important conceptual backdrop for future inquiry and a first framework on which applied practice can be based. 


\section{References}

Arnold, R., Fletcher, D., \& Molyneux, L. (2012). Performance leadership and management in elite sport: Recommendations, advice, and suggestions from national performance directors. European Sport Management Quarterly, 12, 317-336.

Bryant, A. (2009). Grounded theory and pragmatism: The curious case of Anselm Strauss. Forum: Qualitative Social Research, 10(3): Art. 2.

Buchanan, D. A., \& Bryman, A. (2007). Contextualizing methods choice in organizational research. Organizational Research Methods, 10: 483-501.

By, R. T. (2005). Organisational change management: A critical review. Journal of Change Management, 5, 369-380.

Corbin, J., \& Strauss, A. (2008). Basics of qualitative research: Techniques and procedures for developing ground theory (3rd ed.). London: Sage.

Cruickshank, A., \& Collins, D. (2012a). Culture change in elite sport performance teams: Examining and advancing effectiveness in the new era. Journal of Applied Sport Psychology, 24, 338-355.

Cruickshank, A., \& Collins, D. (2012b). Change management: The case of the elite sport performance team. Journal of Change Management, 12, 209-229.

Cruickshank, A., \& Collins, D. (2013). Culture change in elite sport performance teams: An important and unique construct. Sport \& Exercise Psychology Review, 9(2), 6-21.

Cruickshank, A., Collins, D., \& Minten, S. (2013a). Culture change in a professional sports team: Shaping environmental contexts and regulating power. International Journal of Sports Science and Coaching, 8, 271-290.

Cruickshank, A., Collins, D., \& Minten, S. (2013b). Culture change in a professional sports team: A response to commentaries. International Journal of Sports Science and Coaching, 8 , 319-325. 
du Gay, P., \& Vikkelsø, S. (2012). Reflections: On the lost specification of change. Journal of Change Management, 12, 121-143.

Fletcher, D., \& Arnold, R. (2011). A qualitative study of performance leadership and management in elite sport. Journal of Applied Sport Psychology, 23, 223-242.

Fletcher, D., \& Wagstaff, C. R. D. (2009). Organizational psychology in elite sport: Its emergence, application and future. Psychology of Sport and Exercise, 10, 427-434.

Giacobbi, P. R., Jr., Poczwardowski, A., \& Hager, P. (2005). A pragmatic research philosophy for applied sport psychology. The Sport Psychologist, 19, 18-31.

Gimore, S. (2013). Culture change in a professional sports team: Shaping environmental contexts and regulating power - A commentary. International Journal of Sports Science and Coaching, 8, 305-308.

Hardy, C. J., \& Crace, R. K. (1997). Foundations of team building: Introduction to the team building primer. Journal of Applied Sport Psychology, 9, 1-10.

Holt, N. L., \& Tamminen, K. A. (2010). Moving forward with grounded theory in sport and exercise psychology. Psychology of Sport and Exercise, 11, 419-422.

Hutzschenreuter, T., Kleindienst, I., \& Greger, C. (2012). How new leaders affect strategic change following a succession event: A critical review of the literature. The Leadership Quarterly, 23, 729-755.

Judge, T. A., Piccolo, R. F., \& Kosalka, T. (2009). The bright and dark side of leader traits: A review and theoretical extension of the leader trait paradigm. The Leadership Quarterly, 20, 855-875.

Krane, V., \& Baird, S. M. (2005). Using ethnography in applied sport psychology. Journal of Applied Sport Psychology, 17, 87-107. 
Lee, S., Shaw, D. J., \& Chesterfield, G. (2009). Reflections from a world champion: an interview with Sir Clive Woodward, director of Olympic performance, the British Olympic Association. Reflective Practice, 10, 295-310.

Magnay, J. (2013, February 19). Australia's Olympic swimming team was crippled by a 'toxic culture' involving bullying, according to review. The Telegraph. Retrieved from http://www.telegraph.co.uk/sport/olympics/swimming/9879423/AustraliasOlympic-swimming-team-was-crippled-by-a-toxic-culture-involving-bullyingaccording-to-review.html

Morgan, D. L. (2007). Paradigms lost and pragmatism regained: Methodological implications of combining qualitative and quantitative methods. Journal of Mixed Methods Research, 1, 48-76.

Pettigrew, A., Woodman, R. W., \& Cameron, K. S. (2001). Studying organizational change and development: Challenges for future research. Academy of Management Journal, $44,697-713$.

Railo, W. (1986). Willing to win. Utrecht: Amas.

Rynne, S. (2013). Culture change in a professional sports team: Shaping environmental contexts and regulating power - A commentary. International Journal of Sports Science and Coaching, 8, 301-304.

Sam, M. (2012). Targeted investments in elite sport funding: wiser, more innovative and strategic? Managing Leisure, 17, 207-220.

Schein, E. H. (2004). Organizational culture and leadership (3rd ed.). San Francisco: JosseyBass.

Schroeder, P. J. (2010). Changing team culture: The perspectives of ten successful head coaches. Journal of Sport Behavior, 32(4), 63-88. 
Sorge, A., \& van Witteloostuijn, A. (2004). The (non)sense of organizational change: An essai about universal management hypes, sick consultancy metaphors, and healthy organization theories. Organization Studies, 25, 1205-1231.

Strauss, A., \& Corbin, J. (1998). Basics of qualitative research: Grounded theory procedures and techniques (2nd ed.). London: Sage.

Suddaby, R. (2006). From the editors: What grounded theory is not. Academy of Management Journal, 49, 633-642.

Tatlı, A., \& Özbilgin, M. F. (2009). Understanding diversity managers' role in organizational change: Towards a conceptual framework. Canadian Journal of Administrative Sciences, 26, 244-258.

Van de Ven, A. H., \& Sun, K. (2011). Breakdowns in implementing models of organizational change. Academy of Management Perspectives, 25, 58-74.

Wagstaff, C., Fletcher, D., \& Hanton, S. (2012a). Positive organizational psychology in sport: An ethnography of organizational functioning in a national sport organization. Journal of Applied Sport Psychology, 24, 26-47.

Wagstaff, C.R.D., Fletcher, D. \& Hanton, S. (2012b). Positive organizational psychology in sport. International Review of Sport and Exercise Psychology, 5, 87-103.

Wagstaff, C. R. D., Hanton, S., \& Fletcher, D. (2013). Developing emotion abilities and regulation strategies in a sport organization: An action research intervention. Psychology of Sport and Exercise, 14, 476-487. 